\title{
Factors associated with regular physical activity participation among people with severe mental ill health
}

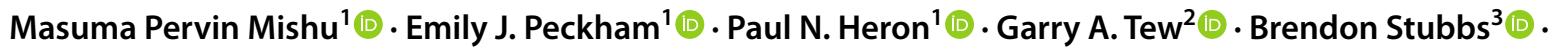 \\ Simon Gilbody ${ }^{1}$ (D)
}

Received: 3 October 2018 / Accepted: 3 December 2018 / Published online: 8 December 2018

(c) The Author(s) 2018

\begin{abstract}
Purpose People with severe mental ill health (SMI) are less physically active and more sedentary than the general population. There is limited research investigating the correlates of physical activity (PA) in people with SMI impeding the development of successful interventions. This study aimed to assess the factors associated with regular participation of PA among a large sample of people with SMI.

Methods The data for this study were collected from the 'Closing the Gap: Lifestyle Health and Wellbeing' (HWB) cohort that collected data through self-administered questionnaire from participants with SMI. Self-reported participation in regular PA was the main outcome variable. Potential predictors of PA were grouped as demographic, biological, psychological and behavioural variables. Multivariable logistic regressions were conducted considering PA participation as the dependent variable adjusted for possible correlated predictors.

Results In total, 3287 people with SMI [mean (SD) age 47.7 (14.58) years, 59\% male] were included; 38\% reported undertaking regular PA and $61 \%$ wanted to undertake more physical activity. Multivariable logistic regressions showed that the following factors were associated with undertaking more regular PA: being male, aged 18-65 years, having a body mass index between 18.5 and $30 \mathrm{~kg} / \mathrm{m}^{2}$, having better self-perceived general health condition, not having a health problem that limits activity, giving higher importance to maintain a healthy lifestyle, and eating more fruit and vegetables.

Conclusions Having a better self-perceived general health and placing importance on maintaining a healthy lifestyle were important predictors of regular PA. Lifestyle interventions targeting increased PA among people with SMI should be shaped by their health perception and informed by their needs.
\end{abstract}

Keywords Severe mental ill health $\cdot$ Regular physical activity $\cdot$ Correlates $\cdot$ Predictors

\section{Introduction}

Severe mental ill health (SMI) is one of the leading causes of disability worldwide, accounting for almost a quarter of all years lived with a disability [1,2]. In the UK, SMI accounts

Masuma Pervin Mishu

masuma.mishu@york.ac.uk

1 University of York, Heslington, York YO10 5DD, UK

2 Department of Sport, Exercise and Rehabilitation, Northumbria University, Northumberland Building, Northumberland Road, Newcastle-upon-Tyne NE1 8ST, UK

3 Physiotherapy Department, Maudsley Hospital, South London and Maudsley NHS Foundation Trust and Institute of Psychiatry, Psychology and Neuroscience, King's College London, Denmark Hill, Camberwell, London SE5 5AZ, UK for around $23 \%$ of the total disease burden and causes significant health and social care costs [3]. People with SMI experience significantly poorer physical health and higher mortality compared to the general population [4-9]. The main cause of decreased lifespan is comorbid physical conditions such as coronary heart disease, diabetes, respiratory, and infectious diseases [9, 10].

It is well-established that physical activity (PA) is associated with a reduced risk of all-cause and cardiovascular mortality [11, 12]. Among people with SMI, systematic reviews have found that PA interventions can improve body composition, quality of life [13], cognition [14], and cardiorespiratory fitness [15]. Some tentative evidence suggests that PA can reduce depressive symptoms, improve quality of life (QoL), increase functioning, and reduce cardiometabolic burden in people with bipolar disorder [16] and people 
with affective disorders [17]. Evidence also indicates that structured physical exercise delivered over 12-16 weeks reduces depressive symptoms in major depression [18]. Consequently, the European Psychiatric Association guidelines now advocate for the use of structured exercise as an intervention for people with SMI, including, schizophrenia, bipolar disorder and major depression [19]. Studies have shown that supervised exercise programmes delivered by qualified exercise professionals result in optimal health outcomes $[14,15,20]$.

Despite the well-established physical and mental health benefits of PA, people with SMI are less likely to engage in PA and are more sedentary in comparison to the general population [21-23]. Recent global meta-analyses have demonstrated that people with bipolar disorder [24] and psychosis [25] engage in very high levels of sedentary behaviour. Given the established benefits of PA and the low levels of PA in people with SMI, there is a pressing need to undertake representative research to explore correlates in this population.

Previous systematic reviews have proposed that PA correlates fit within the socioecological framework in individuals with schizophrenia [26] and with depression [27] including: (a) demographic, (b) biological, (c) psychological/cognitive/emotional, (d) behavioural attributes/skills, (e) social/cultural factors, (f) physical environment, and (g) policy factors. A systematic review conducted by Vancompfort et al. showed that lower self-efficacy, presence of medical co-morbidity, lower educational status, and social isolation were associated with lower PA participation in people with bipolar disorder. Other associated factors were higher body mass index (BMI), older age, financial strains, not being connected to a health care service, and minority ethnicity [28]. Another exploratory study also identified a higher BMI, worse physical fitness, and higher antipsychotic medication dose as independent predictors of higher levels of sitting behaviour in bipolar disorder [29]. Whilst some progress has been made on understanding the factors influencing PA in people with SMI, some limitations exist. First, there is a paucity of representative data on PA in people with SMI with very few studies including over 1000 participants and an absence of such data in the context of the United Kingdom and the National Health Service. Second, most studies have focussed purely on diagnostic-specific correlates [21]. Whilst helpful for people with specific diagnoses, most services include people with different SMIs and understanding broader correlates across the SMI spectrum will help inform the development of interventions for services. Clearly, establishing future successful lifestyle interventions targeting PA for people with SMI will ultimately hinge upon the successful identification and support to address PA barriers and facilitators.
The aim of this paper is to assess the factors associated with participation of regular PA among people with SMI in a large sample, where SMI was defined as schizophrenia or other psychotic disorders, bipolar disorder and depression with psychotic features.

\section{Methods}

The sample of this study was collected from 'Closing the Gap: The Lifestyle Health and Wellbeing' (HWB) survey. The HWB survey is a recently initiated cohort study collecting data on health-related behaviours of people with SMI. In this article, we report on data from the first phase of the study, which ran from March 2016 to October 2017, during which time 3,287 participants were recruited to the cohort.

The HWB study is recruiting participants from both primary and secondary care in England, with 66 NHS primary care general practices (GPs) and 19 secondary care trusts taking part up to October 2017. Detailed descriptions of recruitment methods are reported elsewhere [30]. The eligibility criteria are adults aged 18 and above with a diagnosis of SMI and capacity to consent. We defined SMI as schizophrenia or other psychotic disorders, bipolar disorder and depression with psychotic features (International Classification of Disease (ICD10 F20-29 and F30-31) or Diagnostic and Statistical Manual (DSM IV 295.x, 296.x and 297.x). This classification aligns with the range of diagnoses that would typically be included in a UK primary care-based register of people with SMI for the purposes of quality assurance and reimbursement [31]. Participants were invited to take part either by their mental health team or their GP, who screened their records. Those who met the inclusion criteria were invited for the study. Every effort has been made to ensure that the HWB cohort is as representative as possible of people with SMI. The HWB survey asks questions about physical activity, alcohol use, smoking behaviour, diet, height and weight, demographic information, and willingness to engage in behaviours known to improve health (such as physical activity). Ethical approval for the HWB study was sought and granted by West Midlands-Edgbaston Research Ethics Committee (ref 15/WM/0444, on 23rd November 2015).

\section{The study outcome}

Engagement in regular PA was the main study outcome, and was defined according to response to the HWB survey question 'In general, how often do you take part in any sport or physical activity?'. The answers were: every day, every other day, at least once a week, more than once a month but less than once a week, less than once a month, and never. Later, the variable was dichotomized as the first two groups were 
merged into one group, defined as 'regularly undertaking physical activity', and the remaining answers grouped as 'not regularly undertaking physical activity'. This is in line with Yusuf et al. 1996 who defined regular PA as three or more sessions per week [32].

The other predictor variables were categorized in the socioecological model as follows:

Demographic and biological variables: age (as continuous scale), sex (male, female, transgender, prefer not to say), ethnicity (15 groups), employment status (eight groups) (detailed categories can be found in HWB questionnaire) and BMI calculated from participants' self-reported height and weight. Later, for analysis, sex was re-categorized into three groups (male, female, other); age was categorized as: 18-34 years, 35-64 years and 65 and over; ethnicity was re categorized as white British and other; and employment was re-categorized as: working, retired and non-working, and other. BMI was categorized as 18.5-30, less than 18.5 and more than $30 \mathrm{~kg} / \mathrm{m}^{2}$. BMI categories of $18.5-25 \mathrm{~kg} / \mathrm{m}^{2}$ $(25.83 \%)$ and $25-30 \mathrm{~kg} / \mathrm{m}^{2}(28.53 \%)$ were grouped together, as these two categories did not show significant difference in PA level in this study population.

Psychological/self-perceived health-related factors: this was measured by four questions. First, for self-rated general health, participants were asked: 'How would you rate your general health in the last 12 months?'. Possible answers were: excellent, good, moderate, poor, and very poor. For analysis, the answers were grouped as: excellent to good, moderate, and poor to very poor. The second question in this section, 'Does any health problem limit your activity?', had the possible answers of: yes, no, and don't know. For analysis, the 'no' and 'don't know' responses were merged. The third question, 'How important is it that you maintain healthy lifestyle?' had possible answers of: a top priority, moderately important, and I don't worry about it. Finally, participants were asked 'Would you like to take more exercise?' and participants could choose from: yes, no, and don't know. For further analysis, this variable was converted into a dichotomised variable ('yes' versus 'no and 'don't know') by merging 'no' and 'don't know' responses together.

Behavioural attribute/skill-related factors: To assess healthy eating behaviour, participants were asked 'In general, how many portions of fruit and vegetables do you eat per day?'. Possible answers were: I don't eat fruit or vegetables, one, two, three, four, and five or more portions per day. For the analysis, this variable was converted into a dichotomised variable ('eating 3-5 portions of fruit and vegetables per day' versus 'not eating any fruit and vegetables to eating 1-2 portions of fruit and vegetables per day'). For alcohol consumption, participants were asked 'How often do you have a drink containing alcohol?' which had possible answers of: everyday, most days, weekly, monthly, and never. For analysis, this variable was dichotomised into "not drinking alcohol' ("never" category) and 'drinking alcohol' (all other categories). For smoking, participants were asked 'Do you smoke?' with the following possible answers: yes, no I have never smoked, and no but I used to smoke. The HWB study did not collect information on policy or environmental factors.

\section{Data analysis}

Initially, descriptive statistics and then the bivariate associations between the main outcome and predictors were conducted. The associations between dependent variable (PA) and possible predictors were tested using Chi square test and Chi square test for trend as appropriate to identify variables correlated with PA. Finally, multivariable logistic regressions were conducted to assess the associations between dependent variable (physical activity) and the predictors. The final regression model is based on the existing evidence from the literature and included purposeful selection of predictors [33]: sex, age, BMI, self-rated general health, health problem limiting activity, importance of maintaining healthy lifestyle, smoking, and eating fruit and vegetables. The odds ratios $(95 \% \mathrm{CI})$ were reported and $p$ value of $<0.05$ was set as the statistically significant level.

\section{Results}

Table 1 presents a summary of participants' characteristics. There were 3287 respondents, $59 \%$ of whom were male, and the majority (86\%) were white British. $54 \%$ of the participants had BMI between 18.5 and $30 \mathrm{~kg} / \mathrm{m}^{2}$. A large proportion (59\%) of participants considered themselves as having a health problem that limited their activity. $44 \%$ of respondents considered maintaining healthy lifestyle as a top priority, and $61 \%$ wanted to undertake more exercise. Regarding the personal habit-related factors, $54 \%$ reported eating two or fewer portions of fruit and vegetables per day, $53 \%$ reported drinking alcohol, and $45 \%$ were current smokers. Only $38 \%$ of respondents reported undertaking PA every day or every other day (regular physical activity).

Table 2 presents the bivariate associations between PA participation and potential predictors. Among the patientrelated factors, sex was significantly associated with PA; a greater percentage of males versus females reported undertaking regular PA ( $40 \%$ vs. $35 \%)(p=<0.05)$. Employment status was statistically significantly associated with PA, with more people who were in employment reporting regular PA compared to retired and non-working people (46\% vs. $34 \%$ ) $(p=<0.0001)$. BMI was also associated with PA with fewer underweight $\left(\mathrm{BMI}<18.5 \mathrm{~kg} / \mathrm{m}^{2}\right)$ and obese (BMI $>30 \mathrm{~kg} /$ $\mathrm{m}^{2}$ ) participants reporting regular PA compared to those in 
Table 1 Distribution of the study sample by the potential predictor variables (Max. $N=3287$ )

\begin{tabular}{|c|c|c|c|}
\hline & Variables & Categories & $n(\%)$ \\
\hline \multirow[t]{14}{*}{ Demographic and biological variables } & \multirow[t]{3}{*}{ Sex } & Male & $1917(59.06)$ \\
\hline & & Female & $1303(40.14)$ \\
\hline & & Transgender and preferred not to say & $26(0.80)$ \\
\hline & \multirow[t]{3}{*}{ Age group } & $18-34$ years & $664(20.63)$ \\
\hline & & $35-64$ years & $2141(66.51)$ \\
\hline & & 65 and more & $414(12.86)$ \\
\hline & \multirow[t]{2}{*}{ Ethnicity } & White British & $2802(85.69)$ \\
\hline & & Other & $468(14.31)$ \\
\hline & \multirow[t]{3}{*}{ Employment } & Working & $483(14.97)$ \\
\hline & & Not working, retired & $2203(68.27)$ \\
\hline & & Other & $541(16.76)$ \\
\hline & \multirow[t]{3}{*}{ BMI category } & $\mathrm{BMI}<18.5 \mathrm{~kg} / \mathrm{m}^{2}$ & $432(13.94)$ \\
\hline & & BMI $18.5-30 \mathrm{~kg} / \mathrm{m}^{2}$ & $1687(54.45)$ \\
\hline & & $\mathrm{BMI}>30 \mathrm{~kg} / \mathrm{m}^{2}$ & $979(31.60)$ \\
\hline \multirow[t]{10}{*}{ Health perception-related variables } & \multirow[t]{3}{*}{ Self-rated health } & Excellent-good & $1146(35.07)$ \\
\hline & & Moderate & $1291(39.50)$ \\
\hline & & Poor-very poor & $831(25.43)$ \\
\hline & \multirow[t]{2}{*}{ Health problem limiting activity } & Yes & $1936(59.24)$ \\
\hline & & No and don't know & $1332(40.76)$ \\
\hline & \multirow[t]{3}{*}{ Importance of maintaining a healthy lifestyle } & A top priority & $1444(44.29)$ \\
\hline & & Moderately important & $1272(39.02)$ \\
\hline & & Not important & $544(16.69)$ \\
\hline & \multirow[t]{2}{*}{ Would like to take more exercise } & Yes & $1974(60.74)$ \\
\hline & & No and don't know & $1276(39.26)$ \\
\hline \multirow[t]{7}{*}{ Habit-related variables } & \multirow[t]{2}{*}{ Consumption of fruit and vegetables } & Three or more portions/day & $1494(46.20)$ \\
\hline & & Two or less portions/day & $1740(53.80)$ \\
\hline & \multirow[t]{2}{*}{ Drinking alcohol } & Yes & $1660(53.17)$ \\
\hline & & No & $1462(46.83)$ \\
\hline & \multirow[t]{3}{*}{ Smoking } & Smoker & $1479(45.27)$ \\
\hline & & Never smoked & $956(29.26)$ \\
\hline & & Used to smoke & $832(25.47)$ \\
\hline \multirow[t]{2}{*}{ Physical activity } & \multirow[t]{2}{*}{ Frequency of doing physical activity } & $\begin{array}{l}\text { Rarely does physical activity (once a } \\
\text { week to never) }\end{array}$ & $2034(62.37)$ \\
\hline & & $\begin{array}{r}\text { Regularly does physical activity } \\
\text { (every day to every other day) }\end{array}$ & $1227(37.63)$ \\
\hline
\end{tabular}

the healthy to overweight category (BMI $18.5-30 \mathrm{~kg} / \mathrm{m}^{2}$ ) (32\%, $34 \%$, and $42 \%$, respectively) ( $p=<0.0001)$.

Among the health perception-related factors, selfperceived health status was significantly associated with PA. The frequency of undertaking regular PA gradually increased with better self-perceived health: 'excellent to good' $=48 \%$ compared to 'moderate' $=36 \%$ and 'poor' $=26 \%(p=<0.0001)$. Fewer people who considered themselves as having a health problem that limited their activity reported regular PA $(33 \%)$ compared to those who responded otherwise $(45 \%)(p=<0.0001)$. Self-perceived importance of maintaining a healthy lifestyle was also significantly associated with PA. Among those who considered maintaining a healthy lifestyle a top priority, $51 \%$ took part in regular PA compared to $30 \%$ of those who considered it as a moderate priority, and to $20 \%$ of those who did not care about maintaining a healthy lifestyle ( $p=<0.0001)$. Participants' willingness to do more PA was not significantly associated with their current PA level.

Among the habit-related factors, eating fruit and vegetables was significantly associated with PA. Participants who reported eating three or more portions of fruit and vegetables per day were more likely to report regular PA than those eating two or less portions per day (45\% vs. $32 \%$ ) $(p=<0.0001)$. Smoking was also statistically significantly 
Table 2 Bivariate association of physical activity with possible predictors

\begin{tabular}{|c|c|c|c|c|}
\hline Variables & Categories & $\begin{array}{l}\text { Rarely does physical activ- } \\
\text { ity (once a week to never), } \\
n(\%)\end{array}$ & $\begin{array}{l}\text { Frequently does physical } \\
\text { activity (every day to every } \\
\text { other day), } n(\%)\end{array}$ & $\begin{array}{l}p \text { value }\left(\chi^{2} \text { test and } \chi^{2} \text { test }\right. \\
\text { for trend, where appropriate) }\end{array}$ \\
\hline \multirow[t]{3}{*}{ Sex } & Male & $1147(60.24)$ & 757 (39.76) & 0.014 \\
\hline & Female & $844(65.27)$ & $449(34.73)$ & \\
\hline & $\begin{array}{l}\text { Transgender and pre- } \\
\text { ferred not to say }\end{array}$ & 15 (57.69) & $11(42.31)$ & \\
\hline \multirow[t]{3}{*}{ Age group } & $18-34$ years & $392(59.21)$ & $270(40.79)$ & 0.115 \\
\hline & $35-64$ years & $1327(62.48)$ & $797(37.52)$ & \\
\hline & 65 and more & $268(65.37)$ & $142(34.63)$ & \\
\hline \multirow[t]{2}{*}{ Ethnicity } & White British & $1,741(62.63)$ & $1,039(37.37)$ & 0.871 \\
\hline & Other & $290(62.23)$ & $176(37.77)$ & \\
\hline \multirow[t]{3}{*}{ Employment } & Working & $259(53.62)$ & $224(46.38)$ & $<0.0001$ \\
\hline & Not working, retired & $1,441(65.80)$ & $749(34.20)$ & \\
\hline & Other & $295(55.14)$ & $240(44.86)$ & \\
\hline \multirow[t]{3}{*}{ BMI category } & BMI $18.5-30 \mathrm{~kg} / \mathrm{m}^{2}$ & $967(57.83)$ & $705(42.17)$ & $<0.0001$ \\
\hline & $\mathrm{BMI}<18.5 \mathrm{~kg} / \mathrm{m}^{2}$ & $294(68.37)$ & $136(31.63)$ & \\
\hline & $\mathrm{BMI}>30 \mathrm{~kg} / \mathrm{m}^{2}$ & $639(65.61)$ & $335(34.39)$ & \\
\hline \multirow[t]{3}{*}{ Self-rated health } & Excellent-good & $597(52.28)$ & $545(47.72)$ & $<0.0001$ \\
\hline & Moderate & $819(63.79)$ & $465(36.21)$ & \\
\hline & Poor-very poor & $608(74.15)$ & $212(25.85)$ & \\
\hline \multirow{2}{*}{$\begin{array}{l}\text { Health problem limiting } \\
\text { activity }\end{array}$} & Yes & $1,294(67.33)$ & $628(32.67)$ & $<0.0001$ \\
\hline & No and don't know & $732(55.29)$ & $592(44.71)$ & \\
\hline \multirow{3}{*}{$\begin{array}{l}\text { Importance to maintain } \\
\text { healthy lifestyle }\end{array}$} & A top priority & 709 (49.37) & $727(50.63)$ & $<0.0001$ \\
\hline & Moderately important & $884(69.77)$ & $383(30.23)$ & \\
\hline & Not important & $431(79.67)$ & $110(20.33)$ & \\
\hline \multirow[t]{2}{*}{ Like to take more exercise } & Yes & $1248(63.48)$ & $718(36.52)$ & 0.071 \\
\hline & No and don't know & $765(60.33)$ & $503(39.67)$ & \\
\hline \multirow{2}{*}{$\begin{array}{l}\text { Consumption of fruit and } \\
\text { vegetables (per day) }\end{array}$} & Three or more portions & $823(55.46)$ & $661(44.54)$ & $<0.0001$ \\
\hline & Two or less portions & $1,181(68.23)$ & $550(31.77)$ & \\
\hline \multirow[t]{2}{*}{ Drinking alcohol } & Yes & $1,013(61.39)$ & $637(38.61)$ & 0.253 \\
\hline & No & $921(63.39)$ & $532(36.61)$ & \\
\hline \multirow[t]{3}{*}{ Smoking } & Smoker & $964(65.44)$ & $509(34.56)$ & 0.003 \\
\hline & Never smoked & $557(58.63)$ & $393(41.37)$ & \\
\hline & Used to smoke & $505(61.44)$ & 317 (38.56) & \\
\hline
\end{tabular}

associated with PA. More 'never smokers' were found to do regular PA compared to current smokers and to ex-smokers $(41 \%, 35 \%$ and $39 \%$, respectively) $(p=<0.01)$. Drinking alcohol was not significantly associated with PA.

Finally, the results of fully adjusted multiple logistic regression (Table 3) showed that female participants were less likely to do regular PA than males $(\mathrm{OR}=0.76 ; 95 \%$, CI 0.65-0.90) $(p=<0.01)$ and that those aged greater than 65 years were less likely to do regular PA than those aged $18-34$ years $(\mathrm{OR}=0.61 ; 95 \%$ CI $0.45-0.81)(p=<0.01)$. However, the age group of 35-64 years was not significantly different than the reference age group of 18-34 years. Participants with BMI of $<18.5 \mathrm{~kg} / \mathrm{m}^{2}$ and BMI $>30 \mathrm{~kg} / \mathrm{m}^{2}$ were less likely to do regular PA than those who had BMI between 18.5 and $30 \mathrm{~kg} / \mathrm{m}^{2}$ [OR $=0.70 ; 95 \%$ CI $0.55-0.90$ $(p=<0.01)$ and $\mathrm{OR}=0.83 ; 95 \%$ CI $0.69-0.99(p=<0.05)$, respectively].

Participants' health perception-related variables were found to be important factors associated with PA. Participants with moderate and poor self-rated health were statistically significantly less likely to do regular PA than those who had good self-rated health [OR $=0.82 ; 95 \% \mathrm{CI}$ $0.68-0.99(p=<0.05)$ and OR $=0.55 ; 95 \%$ CI $0.44-0.69$ $(p=<0.0001)$, respectively]. Participants who considered that they did not have any health problems that limited their activity had 1.39 (95\% CI 1.17-1.66) times higher odds of 
Table 3 Result of logistic regression (model with all possible predictors)

\begin{tabular}{|c|c|c|c|c|}
\hline Possible predictors & Categories & OR & $95 \% \mathrm{CI}$ & $p$ value \\
\hline \multirow[t]{2}{*}{ Sex (ref. male) } & Female & 0.76 & 0.650 .90 & 0.002 \\
\hline & Other & 1.20 & 0.502 .86 & 0.681 \\
\hline \multirow[t]{2}{*}{ Age category (ref. 18-34 years) } & $35-64$ years & 0.90 & 0.731 .10 & 0.30 \\
\hline & $65-100$ years & 0.61 & 0.450 .81 & 0.001 \\
\hline \multirow[t]{2}{*}{ BMI category (ref. BMI $18.5-30 \mathrm{~kg} / \mathrm{m}^{2}$ ) } & $<18.5 \mathrm{~kg} / \mathrm{m}^{2}$ & 0.70 & 0.550 .90 & 0.005 \\
\hline & $>30 \mathrm{~kg} / \mathrm{m}^{2}$ & 0.83 & 0.690 .99 & 0.037 \\
\hline \multirow[t]{2}{*}{ Self-rated health (ref. good) } & Moderate & 0.82 & 0.680 .99 & 0.037 \\
\hline & Poor & 0.55 & 0.440 .69 & $<0.0001$ \\
\hline Health problem limiting activity (ref. yes) & No & 1.39 & 1.181 .66 & $<0.0001$ \\
\hline \multirow[t]{2}{*}{ Importance of maintaining a healthy lifestyle (ref. top priority) } & Moderately important & 0.45 & 0.380 .53 & $<0.0001$ \\
\hline & Not important & 0.31 & 0.240 .40 & $<0.0001$ \\
\hline Fruit and vegetables (ref. three or more portion/day) & Two or less portions/day & 0.65 & 0.540 .76 & $<0.0001$ \\
\hline \multirow[t]{2}{*}{ Smoking (ref. Smoker) } & Never smoked & 1.21 & 0.991 .47 & 0.060 \\
\hline & Used to smoke & 1.09 & 0.901 .34 & 0.375 \\
\hline
\end{tabular}

doing regular PA compared to those who considered themselves to have a health problem $(p=<0.0001)$. The odds of doing regular PA for participants who considered maintaining healthy lifestyle as 'moderately important' and 'not important' were 0.45 times (95\% CI $0.38-0.53$ ) and 0.31 (0.24-0.40) times lower (respectively) compared to those who considered maintaining healthy lifestyle as a 'top priority' $(p=<0.0001)$.

Among the habit-related factors, eating fruit and vegetables was significantly associated with PA. Participants who ate two or less portions of fruit and vegetable per day were undertaking less regular PA compared to those who ate three or more portions (OR 0.65 ; 95\% CI $0.55-0.76$ ) $(p=<0.0001)$. Smoking was not significantly associated with PA in this sample after accounting for age, sex, BMI, self-rated health, health problem limiting activity, importance of maintaining a healthy lifestyle, and eating fruit and vegetables.

\section{Discussion}

To the best of our knowledge, the current study is the largest to investigate PA correlates among people with SMI. Of the total sample, $38 \%$ were undertaking regular PA (every day to every other day). After accounting for all factors: participants' sex, age group, BMI, and health-related perception variables: self-rated health, having a health problem limiting activity, and placing importance of maintaining a healthy lifestyle were significantly associated with the frequency of PA participation. Among the habit-related factors, 'eating fruit and vegetables' was significantly associated with PA. The result of logistic regression showed that male participants, ages between 16 and 64 years, and BMI between 18.5 and $30 \mathrm{~kg} / \mathrm{m}^{2}$ were each found to be more regularly physically active. As expected, participants with a better selfperceived general health, and who did not have any health problems limiting their PA, were more regularly physically active. The importance of people's priority for a healthy lifestyle was also a predictor for regular PA as participants who considered a healthy lifestyle as a top priority were more regularly physically active. Finally, those eating three or more portions of fruit and vegetables per day were more regularly physically active compared to their counterparts in this study population.

Previous systematic reviews have shown significant correlations of demographic, biological, psychological, cognitive, behavioural factors with PA among individuals with schizophrenia [26] and with depression [27] and our study supports these findings. These systematic reviews found that, among the demographic correlates, age and gender were the most frequently studied variables. However, none of the correlates was consistently associated with PA participation. A recent systematic review and meta-analysis showed that higher BMI was associated with lower levels of PA participation among people with SMI [21] which was also the case in our study sample. The results of our study are comparable with another systematic review and meta-regression by Vancampfort, which demonstrated that older age and a higher BMI predicted lower PA levels in adults with bipolar disorder [24]. The only other representative study looking at PA correlates in people with psychotic illness, by Suetani et al., also supports the finding [34].

Participants with a better physical fitness and functional exercise capacity were found to be more involved in PA [26]. Physical illness and poor health was considered as a barrier for participating PA [35]. A study with schizophrenia spectrum disorders found that barriers to exercise 
included physical health problems and disinterest and one's psychiatric illness [36]. Similarly, a pilot study found foot and back pain to be important negative predictors of functional exercise capacity in patients with bipolar disorder [37]. Our study found that participants' self-perception of health is also associated with participation in regular PA. The finding of association of regular PA with better physical self-perception is supported by another study that found functional exercise capacity in patients with schizophrenia is reduced not only by obesity and perceived discomfort and pain but also by a sedentary lifestyle and a reduced physical self-perception [38].

Finally, our study also found a significant association between PA and eating fruit and vegetables. A previous study also found protective effects of green vegetables, total fruit and vegetable intake, and various aspects of PA on clinically relevant levels of depressive symptoms [39]. A recent large study among 2407 people with schizophrenia is also in agreement with our paper, which found that inadequate fruit and vegetable consumption and mobility limitations were negatively associated with PA participation [40]. People with SMI are known to eat diets high in processed food and low fruit and vegetable consumption [41, 42]. The systematic review and meta-analysis by Vancampfort et al. found that smoking was associated with lower PA levels [21], but we found no such relationship. Given these findings and the fact that people with SMI in our study wanted to improve their PA and wider lifestyle, future interventions could incorporate these factors together and promote healthy lifestyles for synergistic good effect.

Encouragingly, our study found that approximately $61 \%$ participants want to do more PA and would like support to do so. A previous study published over a decade ago also found that approximately half of the participant psychiatric patients would like help to become more active [23]. Having a desire to change one's own physical activity is the key first step to increasing self-determined motivation and becoming more physically active $[43,44]$. Thus, it would appear from the largest study to date, that less than a third of people with SMI are engaging in regular PA and two-thirds of the whole study population would like help to increase their PA. 62\% of the participants who were not taking regular PA wanted to do more physical exercise (Chi-square test was not statistically significant).

Clearly, there is a need to develop interventions that support people with SMI to increase their PA. A recent systematic review [45] found that, across 32 intervention studies (including 16 randomized controlled trials), very few trials had specifically set out with the primary aim to increase PA, all trials were of small sample sizes (i.e., $<100$ per treatment arm), limited studies had measured objective PA, and the results were equivocal on whether PA can be changed in people with SMI. People with SMI experience a range of motivational barriers and facilitators towards PA [35]. Therefore, clearly an important future step is the need to develop tailored interventions to support people with SMI to increase their PA levels.

Our study has another important implication for clinical practice and further research of PA as an early preventive strategy in this population, as the study found higher BMI and older age as primary barriers towards regular PA. Therefore, this study supports the notion that implementing PA within early intervention services (i.e., from the onset of the illness, when patients are younger, and before obesity and other complications has set in) would be the optimal approach. Research has also shown that PA interventions in young people with first-episode psychosis are highly engaging and beneficial for this population for attenuating the decline in cardiometabolic health conditions that occur with SMI [46].

Inclusion of data on PA from a large sample of people with SMI is a major strength of this study. However, the current findings should be interpreted with some caution due to several methodological considerations. First, all the measures of this study were self-reported. Self-rated measures of PA are not fully reliable as patients may either forget to report or report inaccurate figures for frequency of PA [21, $47,48]$. In addition, our study did not assess the type, duration and intensity of PA. Another limitation is not having information on participants' medication so we could therefore not determine any relationship between regular PA and medication use which is known to influence PA participation [21]. Furthermore, we did not consider information on the built environment and walkability of neighbourhoods [49], and environmental and policy level factors [28] that previous research has demonstrated as important factors. Finally, despite of every effort to ensure that the HWB cohort is as representative as possible of people with SMI in UK, it may be that there are differences between the cohort participants and the general SMI population. However, the fact that these results agree with other previous studies is encouraging. Thus, it is necessary for further research to be conducted to disentangle the relationships between sociodemographic factors, environmental variables, and PA.

\section{Conclusion}

The present study investigated factors associated with regular PA participation in individuals with SMI and found that, along with demographic and biological variables (sex, age, BMI), participants' self-perception of physical health condition and importance of maintaining a healthy lifestyle is associated with undertaking regular PA. The findings supported existing literature that being physically active is a complex behaviour in patients with SMI, as participants' 
psychological and cognitive variables significantly correlated with PA. Given the established multitude of benefits of regular PA participation for physical, mental, and cognitive health in people with SMI, future interventions that target an increase in PA levels are required. Clearly, future interventions targeting people with SMI preferences for PA are required to improve the sedentary lifestyles of this population. Thus, there is a need for studies to focus on understanding barriers, motivation, and preferences for PA to develop healthy lifestyle interventions that aim to improve physical activity among people with SMI that is informed by their needs and shaped by their priorities.

Acknowledgements Simon Gilbody was funded by the NIHR Collaboration for Leadership in Applied Health Research and Care Yorkshire and Humber (NIHR CLAHRC YH) http://www.clahrc-yh.nihr. ac.uk. Brendon Stubbs holds a Clinical Lectureship supported by Health Education England and the NIHR Integrated Clinical Academic (ICA) Programme (ICA-CL-2017-03-001). Brendon Stubbs is also in part supported by the Maudsley Charity and the National Institute for Health Research (NIHR) Collaboration for Leadership in Applied Health Research and Care South London at King's College Hospital NHS Foundation Trust. The views expressed are those of the author(s), and not necessarily those of the NHS, the NIHR, or the Department of Health and Social Care.

\section{Compliance with ethical standards}

Conflict of interest All authors declare that they have no conflict of interest

Open Access This article is distributed under the terms of the Creative Commons Attribution 4.0 International License (http://creativeco mmons.org/licenses/by/4.0/), which permits unrestricted use, distribution, and reproduction in any medium, provided you give appropriate credit to the original author(s) and the source, provide a link to the Creative Commons license, and indicate if changes were made.

\section{References}

1. Murray CJ, Vos T, Lozano R et al (2012) Disability-adjusted life years (DALYs) for 291 diseases and injuries in 21 regions, 1990-2010: a systematic analysis for the Global Burden of Disease Study 2010. Lancet 380:2197-2223. https://doi.org/10.1016/ S0140-6736(12)61689-4

2. Vos T, Flaxman AD, Naghavi M et al (2012) Years lived with disability (YLDs) for 1160 sequelae of 289 diseases and injuries 1990-2010: a systematic analysis for the Global Burden of Disease Study 2010. Lancet 380:2163-2196. https://doi.org/10.1016/ S0140-6736(12)61729-2

3. McCrone P, Dhanasiri S, Patel A et al (2008) Paying the price: the cost of mental health care in England to 2026

4. Razzano LA, Cook JA, Yost C et al (2015) Factors associated with co-occurring medical conditions among adults with serious mental disorders. Schizophr Res 161:458-464. https://doi. org/10.1016/j.schres.2014.11.021

5. Ribe AR, Laursen TM, Sandbaek A et al (2014) Long-term mortality of persons with severe mental illness and diabetes: a population-based cohort study in Denmark. Psychol Med 44:3097-3107. https://doi.org/10.1017/S0033291714000634

6. Holt RI (2012) Cardiovascular disease and diabetes in people with severe mental illness: causes, consequences and pragmatic management: review. South Afr J Diabetes Vasc Dis 9:107-111

7. Brown S, Kim M, Mitchell C, Inskip H (2010) Twenty-five year mortality of a community cohort with schizophrenia. Br J Psychiatry 196:116-121. https://doi.org/10.1192/bjp.bp.109.067512

8. De Hert M, Dekker JM, Wood D et al (2009) Cardiovascular disease and diabetes in people with severe mental illness position statement from the European Psychiatric Association (EPA), supported by the European Association for the Study of Diabetes (EASD) and the European Society of Cardiology (ESC. Eur Psychiatry 24:412-424. https://doi.org/10.1016/j. eurpsy.2009.01.005

9. Osborn DJ, Levy G, Nazareth I, et al (2007) Relative risk of cardiovascular and cancer mortality in people with severe mental illness from the united kingdom's general practice research database. Arch Gen Psychiatry 64:242-249. https:// doi.org/10.1001/archpsyc.64.2.242

10. Correll CU, Solmi M, Veronese N et al (2017) Prevalence, incidence and mortality from cardiovascular disease in patients with pooled and specific severe mental illness: a large-scale metaanalysis of 3,211,768 patients and 113,383,368 controls. World Psychiatry 16:163-180. https://doi.org/10.1002/wps.20420

11. Naci H, Ioannidis JP (2013) Comparative effectiveness of exercise and drug interventions on mortality outcomes: metaepidemiological study. Bmj 347:f5577. https://doi.org/10.1136/bmj. f5577

12. Nocon M, Hiemann T, Müller-Riemenschneider F et al (2008) Association of physical activity with all-cause and cardiovascular mortality: a systematic review and meta-analysis. Eur J Cardiovasc Prev Rehabil 15:239-246. https://doi.org/10.1097/ HJR.0b013e3282f55e09

13. Rosenbaum S, Tiedemann A, Sherrington C et al (2014) Physical activity interventions for people with mental illness: a systematic review and meta-analysis. J Clin Psychiatry 75:964-974. https:// doi.org/10.4088/JCP.13r08765

14. Firth J, Stubbs B, Rosenbaum S et al (2017) Aerobic exercise improves cognitive functioning in people with Schizophrenia: a systematic review and meta-analysis. Schizophr Bull 43:546-556. https://doi.org/10.1093/schbul/sbw115

15. Vancampfort D, Rosenbaum S, Schuch F et al (2017) Cardiorespiratory fitness in severe mental illness: a systematic review and meta-analysis. Sport Med 47:343-352. https://doi.org/10.1007/ s40279-016-0574-1

16. Melo MC, Daher Ede F, Albuquerque SG, de Bruin VM (2016) Exercise in bipolar patients: a systematic review. J Affect Disord 198:32-38

17. Vancampfort D, Stubbs B (2017) Physical activity and metabolic disease among people with affective disorders: Prevention, management and implementation. J Affect Disord 224:87-94. https:// doi.org/10.1016/j.jad.2016.07.042

18. Schuch FB, Vancampfort D, Richards J et al (2016) Exercise as a treatment for depression: a meta-analysis adjusting for publication bias. J Psychiatr Res 77:42-51. https://doi.org/10.1016/j.jpsyc hires.2016.02.023

19. Stubbs B, Vancampfort D, Hallgren M et al (2018) EPA guidance on physical activity as a treatment for severe mental illness: a meta-review of the evidence and Position Statement from the European Psychiatric Association (EPA), supported by the International Organization of Physical Therapists in Mental. Eur Psychiatry 54:124-144. https://doi.org/10.1016/j.eurpsy.2018.07.004

20. Stanton R, Happell B (2013) Exercise for mental illness: a systematic review of inpatient studies. Int J Ment Health Nurs 23:232-242 
21. Vancampfort D, Firth J, Schuch FB et al (2017) Sedentary behavior and physical activity levels in people with schizophrenia, bipolar disorder and major depressive disorder: a global systematic review and meta-analysis. World Psychiatry 16:308-315. https:// doi.org/10.1002/wps.20458

22. Nyboe L, Lund H (2013) Low levels of physical activity in patients with severe mental illness. Nord J Psychiatry 67:43-46. https://doi.org/10.3109/08039488.2012.675588

23. Ussher M, Stanbury L, Cheeseman V, Faulkner G (2007) Physical activity preferences and perceived barriers to activity among persons with severe mental illness in the United Kingdom. Psychiatr Serv 58:405-408. https://doi.org/10.1176/ps.2007.58.3.405

24. Vancampfort D, Firth J, Schuch F et al (2016) Physical activity and sedentary behavior in people with bipolar disorder: a systematic review and meta-analysis. J Affect Disord 201:145-152

25. Stubbs B, Williams J, Gaughran F, Craig T (2016) How sedentary are people with psychosis? A systematic review and metaanalysis. Schizophr Res 171:103-109. https://doi.org/10.1016/j. schres.2016.01.034

26. Vancampfort D, Knapen J, Probst M et al (2012) A systematic review of correlates of physical activity in patients with schizophrenia. Acta Psychiatr Scand 125:352-362

27. Vancampfort D, Stubbs B, Sienaert P et al (2015) What are the factors that influence physical activity participation in individuals with depression? A review of physical activity correlates from 59 studies. Psychiatr Danub 27:210-224

28. Vancampfort D, Correll CU, Probst M et al (2012) A review of physical activity correlates in patients with bipolar disorder. J Affect Disord 145:285-291

29. Vancampfort D, Sienaert P, Wyckaert S et al (2016) Sitting time, physical fitness impairments and metabolic abnormalities in people with bipolar disorder: an exploratory study. Psychiatry Res 242:7-12

30. HWB (2018) The Lifestyle Health and Wellbeing (HWB) survey. https://www.york.ac.uk/healthsciences/research/mental-health/ projects/lifestylehealthandwellbeingsurvey/. Accessed 6 Jun 2018

31. NHS (2010) Changes to QOF 2010/11-NHS Employers. In: GMS Contract. http://www.nhsemployers.org/your-workforce/ primary-care-contacts/general-medical-services/quality-andoutcomes-framework/archive-2006-2012/changes-to-qof-2010-11. Accessed 31 Aug 2018

32. Yusuf HR, Croft JB, Giles WH et alt (1996) Leisure-time physical activity among older adults: United states, 1990. Arch Intern Med 156:1321-1326. https://doi.org/10.1001/archinte.1996.00440 110093012

33. Bursac Z, Gauss CH, Williams DK, Hosmer DW (2008) Purposeful selection of variables in logistic regression. Source Code Biol Med 3:17. https://doi.org/10.1186/1751-0473-3-17

34. Suetani S, Waterreus A, Morgan V et al (2016) Correlates of physical activity in people living with psychotic illness. Acta Psychiatr Scand 134:129-137

35. Firth J, Rosenbaum S, Stubbs B et al (2016) Motivating factors and barriers towards exercise in severe mental illness: a systematic review and meta-analysis. Psychol Med 46:2869-2881. https:// doi.org/10.1017/s0033291716001732
36. Bassilios B, Judd F, Pattison P et al (2014) Predictors of exercise in individuals with schizophrenia: a test of the transtheoretical model of behavior change. Clin Schizophr Relat Psychoses $8: 173-182$

37. Vancampfort D, Wyckaert S, Sienaert $P$ et al (2015) The functional exercise capacity in patients with bipolar disorder versus healthy controls: a pilot study. Psychiatry Res 229:194-199. https ://doi.org/10.1016/j.psychres.2015.07.040

38. Vancampfort D, Probst M, Sweers K et al (2011) Relationships between obesity, functional exercise capacity, physical activity participation and physical self-perception in people with schizophrenia. Acta Psychiatr Scand 123:423-430

39. Ribeiro SML, Malmstrom TK, Morley JE, Miller DK (2017) Fruit and vegetable intake, physical activity, and depressive symptoms in the African American Health (AAH) study. J Affect Disord 220:31-37

40. Stubbs B, Vancampfort D, Firth J et al (2018) Physical activity correlates among people with psychosis: data from 47 low- and middle-income countries. Schizophr Res 193:412-417. https:// doi.org/10.1016/j.schres.2017.06.025

41. Dipasquale S, Pariante CM, Dazzan P et al (2013) The dietary pattern of patients with schizophrenia: a systematic review. J Psychiatr Res 47:197-207. https://doi.org/10.1016/j.jpsychires .2012.10.005

42. Firth J, Stubbs B, Teasdale SB et al (2018) Diet as a hot topic in psychiatry: a population-scale study of nutritional intake and inflammatory potential in severe mental illness. World Psychiatry 17:365-367. https://doi.org/10.1002/wps.20571

43. Vancampfort D, De Hert M, Vansteenkiste M et al (2013) The importance of self-determined motivation towards physical activity in patients with schizophrenia. Psychiatry Res 210:812-818

44. Vancampfort D, Stubbs B, Venigalla SK, Probst M (2015) Adopting and maintaining physical activity behaviours in people with severe mental illness: The importance of autonomous motivation. Prev Med (Baltim) 81:216-220

45. Ashdown-Franks G, Williams J, Vancampfort D et al (2018) Is it possible for people with severe mental illness to sit less and move more? A systematic review of interventions to increase physical activity or reduce sedentary behaviour. Schizophr Res. https://doi. org/10.1016/j.schres.2018.06.058

46. Firth J, Carney R, Elliott R et al (2018) Exercise as an intervention for first-episode psychosis: a feasibility study. Early Interv Psychiatry 12:307-315. https://doi.org/10.1111/eip.12329

47. Firth J, Stubbs B, Vancampfort D et al (2017) The validity and value of self-reported physical activity and accelerometry in people with Schizophrenia: a Population-Scale Study of the UK Biobank. Schizophr Bull. https://doi.org/10.1093/schbul/sbx149

48. Soundy A, Freeman P, Stubbs B et al (2014) The transcending benefits of physical activity for individuals with schizophrenia: a systematic review and meta-ethnography. Psychiatry Res 220:1119. https://doi.org/10.1016/j.psychres.2014.07.083

49. Vancampfort D, De Hert M, De Herdt A et al (2013) Associations between physical activity and the built environment in patients with schizophrenia: a multi-centre study. Gen Hosp Psychiatry 35:653-658 